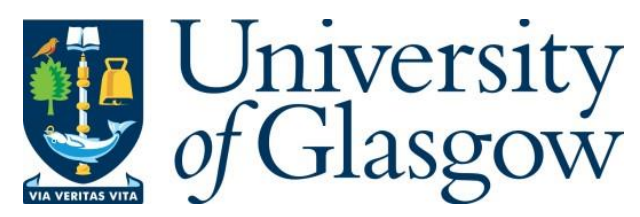

Brennan, I. R., Burton, V., Gormally, S. and O'Leary, N. (2018) Service provider difficulties in operationalising coercive control. Violence Against Women, (doi:10.1177/1077801218797478).

There may be differences between this version and the published version. You are advised to consult the publisher's version if you wish to cite from it.

http://eprints.gla.ac.uk/155856/

Deposited on: 22 January 2018

Enlighten - Research publications by members of the University of Glasgow http://eprints.gla.ac.uk 


\section{SERVICE PROVIDER DIFFICULTIES IN OPERATIONALISING COERCIVE CONTROL}

Pre-print accepted manuscript for publication in Violence Against Women

Iain R. Brennan (University of Hull, i.brennan@hull.ac.uk; School of Education and Social Sciences, University of Hull, Cottingham Rd., Hull, HU6 7RX, UK. Tel. +44 1482 465717)

Victoria Burton (University of Hull; v.burton@hull.ac.uk)

Sinéad Gormally (University of Glasgow; sinead.gormally@glasgow.ac.uk)

Nicola O’Leary (University of Hull; n.oleary@ hull.ac.uk)

\section{AUTHORS' NOTE}

We thank the participants whose interviews underpinned this work and the two anonymous reviewers for their very valuable comments that improved this paper.

\section{FUNDING}

This article was undertaken with financial support from a Criminal Justice Board in England whose name has been withheld at our discretion to maintain anonymity.

\section{KEY WORDS}

Coercive control; Service provider; Police 


\begin{abstract}
We examined perspectives of social workers, police officers and specialist domestic abuse practitioners about their perceived ability and organisational readiness to respond effectively to incidents of coercive and controlling behaviour. Interviews revealed intervention and risk assessment strategies structured around an outdated, maladaptive concept of domestic abuse as an unambiguous and violent event and frontline services that lacked appreciation of the power dynamics inherent in controlling relationships. The analysis demonstrates how lack of definitional clarity around non-physical domestic abuse can increase the use of discretion by frontline services and, by extension, increase the discounting of coercive control by pressured frontline officers.
\end{abstract}




\section{INTRODUCTION}

This paper is drawn from a broader study commissioned by a criminal justice board (a multiagency group with responsibility for oversight of criminal justice and victims service delivery) in England that explored the nature of domestic abuse in the region amid growing concerns that the severity of incidents was increasing. Research interviews undertaken in the summer months of 2015 explored service providers' understandings of this perceived growth in severity. Although not an a priori focus of the study, the imminent introduction of coercive control as a criminal offence emerged as a pressing issue for our participants and an important inter-agency discourse. Our analysis of this issue focused on understandings of the new legislation, definitions of coercive control, service response to cases of coercive control and organisational readiness to treat coercive control and physical abuse as equally important.

To preface the results, this paper demonstrates that at the time of the interviews, with limited resources, lack of definitional clarity and competing demands on all service providers, coercive control was not well understood as a course of conduct and service provider systems and protocols were not prepared to deal with this broader conceptualisation of domestic abuse or accompanying legislation. The interviews reveal services that were not conceptually, structurally or procedurally prepared to respond to abuse that was not violent, which limited the potential for the successful reporting, prevention and prosecution of coercive control offences. The interviews suggest that the ambiguity in definitions of coercive control across services, when coupled with limited resources, can result in an abuse of discretion that leads to the discounting or failure to fully investigage potential cases of coercive control. We frame the solution to these problems within a theoretical underpinning of power, suggesting that a greater appreciation of power and control in relationships would improve frontline response to domestic abuse in all its forms and we emphasise that if organisations wish to deal 
effectively with coercive control, staff must be given the time and resources to investigate this less immediately obvious aspect of domestic abuse. As the paper is drawn from empirically rich data gathered from frontline workers, including social workers, police officers and specialist domestic abuse practitioners, the generic term of service providers is used throughout and whilst there is an acknowledgement of additional specific training or nuanced implementation, this paper provides a unique overview of the needs and deficiencies apparent more generically in service provision in one region in England. It should also be noted that these various service providers are often governed by differing statutory requirements, definitions (Kelly \& Westmarland, 2016), risk assessment strategies (Kelly, Adler, Horvath et al., 2013) and organisational cultures relating to coercive control. This contributes to organisational tensions and inconsistencies, which became apparent in the analysis. Despite the local sample, the lessons learnt here are applicable to domestic abuse services both nationally and internationally, both theoretically and practically, and will inform the future provision of services as more countries seek to criminalise the behaviour and support the victims of coercive and controlling behaviour.

\section{Defining Coercive Control}

Physical abuse is an important component of domestic abuse but researchers and domestic abuse support organisations and advocates have long sought to emphasise that, in addition, isolation, emotional harm, manipulation, coercion and threats of harm are frequent features of an abusive relationship. Furthermore, agencies have also sought to emphasise that it is these features of abuse that often have longer and greater impacts on a victim than physical violence. When it came into force in December 2015, the Serious Crime Act (2015) made coercive and controlling behaviour a criminal offence in England and Wales and defined them accordingly: 
Controlling behaviour is: a range of acts designed to make a person subordinate and/or dependent by isolating them from sources of support, exploiting their resources and capacities for personal gain, depriving them of the means needed for independence, resistance and escape and regulating their everyday behaviour. Coercive behaviour is: a continuing act or a pattern of acts of assault, threats, humiliation and intimidation or other abuse that is used to harm, punish, or frighten their victim (Home Office, 2015).

Stark (2007) asserts that a range of coercive and controlling behaviour frequently underpins physical abuse by a domestic abuse perpetrator and significantly, this is symptomatic of wider gendered, inequality - a perspective supported by Hester (2011), Kelly and Westmarland (2016) and Williamson (2010). Furthermore, research underscores that the coercive and controlling aspects of abuse have the most pervasive and destructive consequences for victims (Yllo, 1993; Golding, 1999; Humphreys \& Thiara, 2003; Harne \& Radford, 2010; Williamson, 2010; Laing, Humphreys, \& Cavanagh, 2013; Crossman, Hardestry, \& Raffaelli, 2015; Pitman, 2016). Central to Stark's concept of coercive control are the use of 'intimidation, isolation and control' (2007:5). He argues that domestic violence is a 'liberty crime' (2007: 13), stripping away a victim's sense of self and more broadly violating their human rights, thus locating it within a wider feminist perspective of gender inequality referred to earlier. Stark (2007) asserts that the patterned nature of coercive control must be understood in the context of gender oppression and that failure by service providers to recognise this structural violence will lead inevitably to a diluted organisational response to coercive control compared to physical domestic abuse or a focus solely on the physical features of an abusive relationship. Kelly and Westmarland (2016) have suggested that by 
describing coercive control as potentially an 'incident', the definition of coercive control reinforces the flawed understanding of coercive control as a series of independent events.

Coercive and controlling behaviour can take a variety of forms and leaves little physical evidence, which inhibits its easy identification by victims, first responders and service providers (Myhill \& Hohl, 2016). As a course of conduct rather than a single episode, recognising a pattern of coercive control requires an appreciation of the wider gendered context of power relations in intimate partnerships, the availability of historical information and a readiness to link a diverse range of abusive behaviours. A prerequisitve of linking these abusive behaviours is an appreciation of the cumulative weight that persistent and pervasive controlling behaviours can have on a victim. For frontline responders, this evidence is rarely immediately apparent and often requires them to ask the right questions of the victim. In the absence of resources and knowledge, service providers may fail to identify this behaviour, disproportionally emphasising physical violence as a marker for immediate or high risk. Evidence suggests this alone is not an accurate predictor of domestic violence homicide: recent separation, weapon presence and high levels of control are more likely to lead to threat to life (Campbell, Webster, Koziol-McLain et al., 2003) underscoring the significance of coercive control. However, the vast range of behaviours that can be viewed as controlling or coercive may undermine a service provider's confidence to label coercive control as such. Furthermore, the broad range of potential behaviours that can form a pattern of coercive control imbue, by default, discretion on the part of the responder in their decision to record an offence (Myhill \& Johnson, 2016). At times of organisational change and limited resources a typical feature of contemporary domestic abuse services in England and Wales - service providers may be less willing or able to search for this pattern. 
Coercive control is complex and the strategies used by a perpetrator are nuanced, frequently linked to the minutiae of an individual relationship (Stark, 2007; 2013; Williamson, 2010) and the micro-dynamics of power and control. This involves multiple dimensions of psychological abuse, whereby tactics include coercion, threats (to the victim, children and pets), intimidation, financial abuse (money for essential items such as food or petrol is restricted/withheld), reinforcing invisibility and isolation (Dobash \& Dobash, 1992). Importantly, physical abuse is not necessary to control, but it remains an ever-present threat (Stark, 2007). Humphreys and Thiara found themes of severe emotional distress, which emanate from a loss of identity, confidence and esteem; '...I didn't see it as violence; being shouted at, I just thought I was too weak. You get worn down by it over years, you think you are useless, you think you are worthless, you think you are hopeless.' (2003: 214). The abuse is frequently complex and all consuming: Johnson (2008) described it as 'intimate terrorism'. While it infiltrates many areas of the relationship it can continue undetected to outsiders, increasing feelings of powerlessness and disconnection to wider social networks. Given the invisibility of many of the mechanisms of coercive control to those outside the relationship, emerging research suggests that this form of abuse is difficult to identify, assess and respond to in practice (Pitman, 2016; Robinson, Pinchevsky, \& Guthrie, 2016a). The impact of living with persistent fear, the insidious nature of the abuse combined with the severe emotional distress this can generate, have become defining features of coercive control, yet is harder to identify, less visible and therefore arguably is a lower priority for professionals focused on identification of high risk cases through a lens of pursuing criminal convictions (Westmarland \& Kelly, 2012; Robinson, Pinchevsky, \& Guthrie, 2016b).

Recent research by Pitman (2016) highlights a sophisticated inter-relationship between coercive control and physical violence, suggesting that coercive control is the more likely of 
the two to evade identification and understanding by service providers. The accounts in Pitman's research illustrate the complexity and penetrating nature of abusive relationships that ultimately lead to women being held in place by fear of threat, violence and retaliation. She asserts that the identification of coercive control 'can evade professional judgement' (2016: 14) and frequently does not factor in decision-making or assessment processes. One of the significant findings of Pitman's study was that regardless of experience of physical violence, accounts of the patterns and consequences of coercive control were consistent. Whilst the sample was relatively small (30 women), these findings suggest that the common denominator of coercive control abuse cases were that the techniques used by abusers were sophisticated and often nuanced. This highlights the difficulty in both understanding and working with coercive control when professional systems are geared up to deal with single, unambiguous incidents of physical violence (Stark, 2007; Hester, 2011; Robinson et al., 2016a). In addition, Hester (2011: 841) suggests that while the 'criminalisation of domestic violence' has been significant in shifting the issue from the private to public domain, a continued focus on single incidents of physical harm means coercive control continues unchecked.

\section{METHOD}

\section{Procedure And Sample}

Commissioned by a regional Criminal Justice Board in England, this research sought to broadly explore the characteristics of domestic abuse incidents, victims and perpetrators, the perceived increase in severity of domestic abuse and the potential of predictors of repeat victimisation. However, what emerged from the qualitative data analysis, were issues, conflict and apprehension around the ability of frontline individuals and service provider organisation to identify and react appropriately to incidents of coercive control. Ethics 
approval for the study was obtained from the University of Hull Social Sciences Ethics Committee in June 2015.

During the months June to August 2015, the authors conducted and analysed 35 semistructured interviews with respondents representing a range of voluntary and statutory agencies involved in the prevention and management of domestic abuse in the region. Respondents were of varying levels of seniority: from frontline service practitioners and police officers, through to managers at a more operational and strategic level. This sampling strategy allowed us to obtain a broad perspective on response to domestic abuse in those organisations: from frontline implementation to strategy development. Using a convenience sample, we relied on self-selecting and 'directed' volunteers and the research team's own contacts within the service provision sectors. From these initial contacts, information about the project was disseminated and the sampling developed its own momentum and a type of networking system of recommended participants emerged (Sharpe, 2000). All interviews were audio-recorded and the interviews were transcribed prior to analysis.

\section{Analytic Method}

Data were examined by the authors to identify emergent themes using the principles of grounded theory (Glaser \& Strauss, 1967). Given that the original focus of this research was not specifically on responses to coercive control, in the tradition of qualitative research the direction of the study was responsive to the data and adaptive to new themes that may alter the perception of the original framework (Layder, 1998; Bottoms, 2000). This, in turn, impacted on the discussions undertaken with participants later in the sampling. Several substantial and coherent issues in relation to operationalising coercive control emerged: these are presented and discussed below. The findings begin with an analysis of the role of power 
relations in service provision and this is followed by an analysis of service provider preparedness for effectively managing cases of coercive control. The two arms of the analysis are drawn together in the concluding section.

\section{FINDINGS}

\section{Power, Coercive Relationships And Service Providers}

Peckover has effectively utilised a Foucauldian lens on governmentality to explore how domestic abuse is constructed within public policy finding that 'health and social care professionals [are] expected to adopt regulatory roles' (2014: 1780-1781) through techniques of surveillance. Importantly, she asserts that despite domestic abuse becoming embedded in everyday professional discourse, specifically in child welfare, this does not result in detailed understanding. Peckover also notes that awareness of the issues does not necessarily mean professionals are adequately equipped to deal with them (ibid).

The notion of power is multifaceted and, inevitably, the new offense of coercive control therefore increases the impact of governmentality on the professional's role. The increased focus on them recognising coercive control places an impetus on practitioners to have the capacity to understand the nuanced, complicated and fluid nature of power and control. As Foucault (1980a: 51) asserts the "exercise of power itself creates and causes to emerge new objects of knowledge and accumulates new bodies of information". Clearly the exercise of coercive power has created new knowledge in its causal link to physical domestic abuse and to the detrimental impact on the victim. Institutions and systems produce 'coherent systems of knowledge' and can validate power (Ball, 2013: 13) or arguably, facilitate awareness of the micro-dynamics of control in everyday life. 
...If power is in reality an open, more-or-less coordinated (in the event, no doubt, illcoordinated) cluster of relations, then the only problem is to provide oneself with a gird of analysis which makes possible an analytic of relations of power (Foucault, 1980b: 199).

The position of power available to professionals in establishing "regimes of truth" (Foucault, 1980b) can therefore be used as a positive discourse that challenges coercive control. Professionals can only engage in effective surveillance and management of coercive control if they have the knowledge and understanding of the negative power abusive men exercise.

Subsequently, if we view power as a "productive network which runs through the whole social body, much more than as a negative instance whose function is repression" (Foucault, 1980c: 119), then we can assess power as the "ability or capacity to act" (O'Brien \& Moules, 2007: 397) and make a difference in empowering victims, service providers and the policing of coercive control in questioning how both victim and offenders 'know' and act on power in their lives.

The police must recognise such behaviours as controlling and coercive and offer the relevant support in addition to actively utilising the Serious Crime Act (2015) in punishing such offences. However, this still needs work. As Medina Ariza, Robinson and Myhill (2016: 5) note in relation to police identification of coercive control:

It would appear from on-going research though that the 'narrative' around risk in forces remains largely one of physical violence, and that despite there being scope to 
do so, many frontline officers do not provide sufficient context when completing risk assessments to illuminate coercive control.

The ways and means perpetrators use such behaviours can make identification or even recognition of coercive control problematic. The traditional focus on physical evidence has clearly resulted in frontline policing not effectively utilising the new powers granted to them under the Serious Crime Act 2015. Under this Act coercive and controlling behaviours are an offence, which can be punishable with up to five years' imprisonment. However, a report by the BBC Radio 5 Live (BBC, 2017) established that, of 25 of the 43 police forces in England and Wales who responded to a Freedom of Information request, the new law had been used just 202 times in the first 12 months with 2 forces not charging a single person with the offence. Without identifying such negative controlling behaviours, the vicious circle will continue with few perpetrators being punished and the cycle of controlling, coercive and exertion of negative power will likely endure.

\section{$\underline{\text { Power And 'Control' In Coercive Control }}$}

As this paper asserts, power has a dynamic, shifting relationship when analysing coercive control. As this interviewee states, there is a need to be aware of these power dynamics in the assessment of risk and that having a broader understanding of control will influence how events are perceived and understood, in turn linked to professional responses.

The different types of power and controlling behaviours and how risk is assessed and that if a person were to look at undermining comments or disparaging comments against one partner or another, they might not trigger alarm bells, but in actual fact it's a key indicator that there's other stuff going on. So yes, I think if we accept that 
not everybody has that full, considered understanding of the power and control dynamic then they're bound to interpret incidents in different ways and at different risk levels. Interview 19

The respondent continues:

My perception is that some agencies are completely bought into the underpinning ethos of power and control, the underpinning mechanism around power and control, but some aren't. Some, I think, even though they might not articulate it in this way, see domestic violence as a series of unrelated incidents. Interview 19

Within this interview there is a clear recognition of the negative form power can have but equally there is acknowledgement of the difficulties in identifying these behaviours as indicators of control and oppression. This feeds into the need for all services to be trained in power analysis and more broadly on coercive control thus allowing them to play a significant role in supporting victims and perpetrators in their recognition of this negative power dynamic. The identification of control in coercive control is vital in service provision. However, as this interviewee also highlights there are inconsistencies in the recognition and application of this analysis.

I think as you start to get broader around the statutory agencies, there will be inconsistencies about how people interpret or think about making a referral through to MARAC, ... but if I can give you an example... [interviewee details an example of a young woman who repeatedly presented at health services, always in the presence of a partner] ...And the service hadn't made a MARAC referral because at no point had 
they observed any physical injuries on her and had followed the risk assessment process to the letter and done the scoring, but it wasn't until actually we flagged up as part of the ward work we were doing that you can use your professional judgement and actually [repeated presentation of this nature] is a risk. So that brought it to light and we dealt with it... Interview 19

Despite coercive control being a 'liberty crime' that is symptomatic of the broader male hegemonic society we live in and the erosion of the rights of women (Stark, 2007), another interviewee analyses controlling behaviours as a precursor for more physically violent and aggressive behaviours. While coercive control in itself can be life-limiting, her analysis suggests that increasing awareness about the harms of non-physical abuse could also prevent incidents of physical abuse:

'...it starts off with a bit of control, "You're not going out," or, "You're not wearing that," then a bit of putting them down, isolating them, then a bit of pushing and shoving, then the it seems to go bang quite quickly, certainly with young people’.

\section{Interview 1}

The specific reference to young people additionally highlights the need for educational services to be aware of coercively controlling behaviours, strategies for identification of these behaviours and ways of addressing, reporting and gaining support if a victim of such behaviours. The lack of identification of these behaviours additionally demonstrates the need for empowering young people in feeling confident in articulating and recognising coercive control as a negative manifestation of power. 


\section{$\underline{\text { Power As Fluid, Widespread And Multidimensional }}$}

Part of the educational process for the public and service providers about coercive and controlling behaviour must be on the multidimensional nature of power and control. Here, the mechanisms of control and power are shown to be complex and nuanced:

\footnotetext{
So the way we talk about power and control as well, I think there's a little bit of perception of someone being a dictator or getting off on power because...just because we use the phrase power and control... whereas actually it's about how he's managing his insecurity because that's understood, but we forget actually that, while that person is power grabbing, actually they feel really insecure and actually perhaps need some help around recognising that. Interview 13
}

The hegemonic aspect of power (Gramsci, 1971) where ideas and norms are deemed as pervasive and 'hidden', may result in an unconscious acceptance of particular aspects of male dominance.

It's the whole nature, it's not a stranger is it, I mean it's an intimate thing; you're living constantly day-by-day. I mean I reckon the repeats are massive, but it's what we class as... do we class telling her to 'Fucking get my tea ready' as a repeat? No police won't think that, but on a constant day that just goes above and beyond repeat.

\section{Interview 12}

Part of recognising this power is done through a broader awareness of the societal structures in which we live and engage: this in turn feeds directly into the high repeat nature of domestic abuse as highlighted by Stark (2007) and epitomised by the quotation above from a 
service provider. Coercive control reflects wider structural inequality and there needs to be a consciousness of broader gender inequalities (Stark, 2007; 2013) to create a counterhegemony (Gramsci, 1971) in striving for a more gender equal society. These interviewees above note the need to work with police, service providers, victims and perpetrators in recognising these controlling behaviours and the potential for repeat victimisation within these relationships.

As noted above there can be the beginning of an empowerment process where services work with victims in the identification of controlling behaviours and support the victim to move away from the relationship if required. Adopting a more positive view of power begins to create an empowerment process, which builds the capacity and agency of the victim. This empowerment process needs to be critically reflective of practice, which at times can be tokenistic. Practitioners need to be aware of multi-level power dynamics and ensure they do not subscribe to a 'power over' model more than 'power with' victims in assessing their needs and building their own capacity to act.

There's the whole cycle that those relationships go through linked to power and control. So after an incident a perpetrator may have a period of remorse ...change their behaviour temporarily, which makes the woman think, 'oh well perhaps he has changed his ways'. And therefore, the relationship falls back into being active, but then the violent and controlling behaviour builds up again until the next incident and so on and so forth, and there is that cycle that's gone through. I think for me, effective arrest and prosecution of incidents may curtail that cycle. And there's something about for support services to intervene at an earlier stage ...to recognise the power 
and control dynamic that's going on ... and getting in there as early as possible.

\section{Interview 19}

This quotation depicts the difficulty in not only defining these behaviours but also responding to them effectively from a professional perspective. Services need to identify the controlling behaviours in a time efficient manner but as noted below, this would rely on a unified understanding of coercive control and clear partnership working to support the woman as necessary.

\section{$\underline{\text { Definitional Issues And Professional Responses }}$}

Our analysis revealed much implicit tension regarding the definition of domestic abuse and variation in frontline practitioners and first responders' professional responses to these incidents. In particular, old and new working definitions of domestic abuse created tension, partly because of the perceived homogeneity in offences that a new, broad definition of domestic abuse could create[Footnote 1]. Furthermore, some respondents believed that the grouping of adolescent-on-parent violence, partner violence and coercive and controlling behaviour into a single category, 'domestic abuse' (Home Office, 2012), was unhelpful as it prompted a homogeneous response to these very different forms of abuse.

As the interviewee below notes, there are problems in grouping various types of abusive behaviours without recognising the varying use of power across these offence types. Observing the vastly different characteristics of familial violence and controlling behaviour both nominally 'domestic abuse', this respondent demonstrates the organisational obstacles to the understanding of coercive control by service providers. 
I think there's something about lumping together familial violence and domestic violence with domestic abuse that doesn't recognise the power and control dynamic. So yes, it's a problem and I don't deny it's a problem that we need to deal with, but siblings having a punch up or adolescent behaviour that deteriorates such that the parent loses control and can't maintain a safe environment is very different to a partner exercising power and control through all the means that we know about with all the women and children. So I think it needs a much more nuanced approach to dealing with it rather than trying to lump it all together. Interview 19

Fortunately, it appears that specialist police staff have a well-evolved understanding of the differences between these types of abuse and are well-equipped to treat these situations as being aetiologically different and requiring different police responses. However, this was not the case across the whole Force. Some interviewee's identified a distinction between call handlers, first responders and specialist officers:

If you're looking at (specialist) staff, I think they have a very good understanding of the whole array of abusive behaviours, but I think when you look at the officers that are dealing with ... going out to incidents, I think there is a lack of understanding around the whole coercive control stuff... a lot of police officers just don't get it. They really don't get it. I think they just think, well, there's no visible injury, and there's no ... it's a verbal argument, what's the problem? Interview 10

Developing, enhancing and embedding understandings of coercive control in frontline services has relevance for not only the police service, but also many other frontline staff and specialist agencies given the newly introduced legislation criminalizing coercive control. For 
example, some of those working in the health care sector may be well placed at times to recognize a coercive controlling situation and the nuanced nature of such a presentation, however difficult and nuanced this may be. The two respondents below address the potential important role of frontline health workers for example:

I think the Health Service don't recognise the impact they could have around violence in many forms, but I guess particularly domestic violence, they've got a critical role to play. I know everybody is busy. As soon as you mention the word (domestic) violence it's got to be a police matter. Interview 13

It's partly about the definition and the wider societal context of how domestic abuse and violence is perceived. The old chestnut of 'well, why didn't she leave' or' surely she must have done something to provoke it', those attitudes still pervade and people who work in the National Health Service also live in society and don't necessarily have exposure to the thinking process that would support a coercive control process.

\section{Interview 19}

The quotes above allude to the difficulties in both understanding and working with gendered notions of coercive control, where current professional systems across many institutions and sectors are geared towards dealing with single incidents of physical violence as opposed to the range of abusive behaviours which underpin coercive control, inclusive of physical abuse (Stark, 2007).

\section{The Dynamics Of Risk And Risk Assessment}


The current criminal justice focus perpetuates an emphasis on discrete physical injury or isolated incidents and responding to these incidents with arrest or assessments of risk of future harm to a victim. Indeed, many tactics of coercive control can evade professional assessment and attract no intervention or legal standing (Pitman, 2016; Stark, 2007). Within this research study, some specialist service providers urged caution with regard to the current models of risk assessment and mechanisms to manage this - the DASH risk assessment checklist [Footnote 2] and MARAC (Multi-Agency Risk Assessment Conference) [Footnote 3] processes - asserting that a primary focus on high-risk and immediate physical assault and the associated reduction in reoffending is a false economy:

My only concern about MARAC is that... we focus completely on high risk and I bet seventy percent of the ones I've read...they came in as low risk, so if we're talking about murders, we don't just need to be talking about high risk. Interview 11

To further illustrate this point, another specialist service provider discussed a historical domestic violence homicide review:

That was a standard risk case, and there was absolutely nothing within that case that you would look at and think would have led to what had happened. But I was looking at the report yesterday... and when you actually look at it now, knowing what you know now around coercive control, there were massive indicators around coercive control within that case. Interview 10

It is clear that in the current climate of limited resources, risk management dictates resource allocation - efficiency and prioritising being an underlying aim of all risk assessment. This 
focus on triaging cases diminishes the importance of coercive control because the risk assessment tools are designed to focus on physical violence and prevention of fatality, placing much less emphasis on non-violent behaviours (Hester, 2011; Westmarland \& Kelly, 2012; Myhill \& Hohl, 2016; Pitman, 2016). Another respondent below echoes this point:

And then they'll [police officers] go away and leave the situation, where actually, we know evidentially that standard and medium risk cases where there's a high level of coercive control are more likely to end up in domestic homicide. Interview 10

The combination of limited resources, varying definitions and actuarial risk assessment that prioritises violent abuse over non-violent abuse means that it will always be difficult to deliver a uniform response to domestic abuse and more specifically, even when it is recognised, to coercive control. The DASH risk assessment does provide some guidance with risk scores (Myhill \& Hohl, 2016). Despite this, almost all of the respondents in our study asserted their confidence in the use of professional judgement in assessing risk. Officers and frontline service providers need to be able to recognise the continuous and cumulative nature of coercive control in order to then recognise the importance of identifying and assessing accurately the apparently low level incidents of domestic abuse. It is clear from the evidence above that inconsistent understandings and inadequate investigation, risk assessment and recording of particular incidents and crimes can prevent robust documentation and of the context and history of abuse. This inevitably results in missed opportunities for early intervention and on-going management of risk.

\section{Discretion And Non-Physical Abuse}


Police officers in England and Wales have a great deal of discretion in how they deal with incidents of domestic abuse. Recently, Myhill and Johnson (2016) have discussed the decisions faced by officers in defining incidents as domestic abuse and the influence of culture and risk assessment technologies in these decisions. Notably, this paper was one of the first to address officer discretion in responding to non-physical abuse, a theme that we advance here. Our interviews revealed that, for officers, the broad range of behaviours that constitute coercive control gives officers greater discretion in identifying cases as coercive control. Furthermore, this inconsistency - and, by extension, under-recognition of cases of coercive control - protects other service providers from becoming overwhelmed by service users who have been victims of coercive control.

A dominant theme through many of our interviews was that frontline responders are required to use discretion, but that it is not always used appropriately, supporting the findings of Myhill and Johnson (2016). Indeed, the use of discretion by police responders allows the seriousness of coercive control cases to be minimised or even not recognised at all. Therefore, regardless of official definition, these responders influence what coercive control is and is not in practice and, consequently, how the police and their partner agencies respond to it:

But everybody interprets risk differently, some are more risk averse, some are more happy. Interview 1

Trying to get the staff to fully understand the intricacies of it and, and the unique nature of that relationship between sort of victim and perpetrator...that's a bit of a kind of, an area for development still. Interview $\mathbf{2}$ 
The most significant factor shaping the way discretion is exercised in relation to domestic abuse and coercive control is an individual's knowledge of the issue. Myhill and Johnson (2016) noted that where there is lack of nuanced understanding of the dynamics of coercive controlling abuse, officers are unable to respond consistently and effectively. Where officers involved regard a particular incident as being of no or low risk, there was often a lack of understanding that in some cases minor incidents are symptomatic of a course of conduct, the impact of which is cumulative for the victim (ibid.) Many of our frontline respondents referred specifically to notions of control and power when discussing practical definitional and contextual issues. It is also clear that even for those with a professional awareness and recognition of coercive control, being aware of the new legislation does not mean that they are organisationally equipped to respond in a practical way to that concept. Furthermore, the way in which police interpret cases of coercive control impacts on the activities and workloads of services downstream. Referring specifically to police call handlers who may be the first point of contact for vicitms of domestic abuse, this problem is keenly illustrated in the quote below:

If they get it wrong at that first point of contact then you're sending the wrong resource or you're not sending another resource at all, you're not correctly identifying the risk, whether that's risk to the victim or risk to children...So the big issues are around knowledge and experience... making sure that they've got the appropriate level of supervision to make sure that we're not missing opportunities...

This respondent continues:

...there's been a process of training going on to upskill those officers but again it's around making sure people have got the right attitude, the right perceptions and they, 
understand the nature of domestic abuse and why it's different from other areas of crime. Interview 2

These concerns were echoed by other respondents who were troubled by the effect that the definitional 'fluidity' of coercive control was having on the practice of dealing with the victims' and perpetrators of domestic abuse:

We don't even name it in the MARAC you know, we don't say that's coercive control, and, if we start to do it right then, then we're certainly going to see another huge increase [in numbers]. Interview 4

When discussing the definition, use and application of new legislation regarding abusive behaviour, referring specifically to coercive control legislation, the same respondent hinted as to what the potential consequences for statistical outcomes and workload could be if the statute definition and practices were adhered to:

I think that there is a huge issue around coercive control and if the Government get this right and this law and its implementation is right then we're going to have a problem because I think that as agencies, even us as specialist services are still not identifying and labelling coercive control correctly and responding to it as such.

\section{Interview 4}

This quote summarises neatly tensions apparent at all levels and across many service providers: that a lack of consensus over the definition of coercive control is, perversely, protecting services from a deluge of victims but failing those in need of their support. 


\section{CONCLUSION AND IMPLICATIONS}

This research indicates that, despite the recent definitional changes in England and Wales, for many practitioners working in domestic abuse intervention and support, physical violence remains the defining feature of domestic abuse. This is unlikely to have changed since the introduction of the new coercive and controlling behaviour legislation in December 2015. For many, coercive control is simply a precursor to the more important physical abuse; or a characteristic of abusive relationships that are only recognised after serious harm has been suffered. In practice, coercive control is poorly understood: if front line service providers, including police officers, had a better understanding of coercive control as a pattern of behaviour and the ways in which power is exercived in abusive relationship, they would be better placed to identify this nuanced chain of events. In addition, this research shows even when specialist agency practitioners do recognise coercive control they are not always in a position to respond to it effectively. Until frontline staff (across all agencies) start to reconceptualise domestic abuse and consider the overall gendered context of coercive control, thinking about domestic abuse being both physical and non-physical - both episodic and continuous - the failure to recognise the significance of apparently low-level incidents of domestic abuse will persevere. The learning curve for such a change in attitudes is likely to be steep and change slow in services that have not traditionally seen domestic abuse in this way, but many victims will be poorly served until these changes occur.

The research also identified a lack of consensus in the definition of coercive control that has been highlighted by others (Kelly \& Westmarland, 2016). In theory, this lack of consensus should not create problems within services. However, the commitment to multi-agency cooperation in today's domestic violence prevention environment makes differing definitions 
impractical and potentially leads to less obvious forms of domestic abuse being missed, discounted or ignored. The lack of consensus causes, or at least facilitates, discretion on the part of frontline service workers about how to record and manage incidents of non-physical abuse. In a time of limited resources and large caseloads, the organisational incentive to minimise the recording and importance of non-physical abuse is considerable. This temptation is compounded by an actuarial assessment, the DASH, which emphasising physical violence over non-physical violence. Existing systems, tools and practices among domestic abuse staff and organisations are not well-prepared for addressing coercive control. Steps to maximising the multi-agency service provided to victims would be made by ensuring that services are working to identical definitions, by services accommodating the increased amount of resources required to identify and manage cases of coercive control and by ensuring that those resources are available to statutory organisations.

Current systems across many jurisdictions focus on single incidents of physical violence and a reduction in repeat victimisation but this belies the complex and sophisticated mechanisms of controlling behaviours that are often part of abusive relationships (as Pitman, 2016 also states). The development of policy and practice that is responsive to non-physical features of abuse must begin with an analysis of how negative power affects victims and their interaction with support services. The understanding that coercive and controlling behaviour may be a precursor to violence should not be used as the sole reason for identifying and responding to coercive control, rather coercive control should be analysed within the broader sphere of gender inequalities and become an intrinsic part of practitioner analysis, regardless of the cooccurrence of physical violence. 
This paper demonstrates that social workers, police and all specialist providers need to conceive of coercive control as an issue that requires the attention of all domestic abuse service providers and a recognition of how one agency's response to a case of coercive control can affect that of another. This paper also demonstrates the need for further, continuous multi-level analysis of the implementation of the recent coercive control legislation. This analysis must ascertain if and when changes in the policy creation or response are needed and how the legislation is enacted in practice. This research uniquely explores the lived experiences and, critically, the tensions between different agencies and personnel working within the field of coercive control and domestic abuse, whose commonality centres on their struggle to operationalise this theory and understanding into their practice. Assessment for a pattern of coercive control is critical for best practice in domestic abuse (Pitman, 2016) especially as the tactics are often resonant of the normative constraints for women in society and can reflect wider gendered inequalities (Stark, 2007), which can reinforce invisibility and be particularly hard to identify. We argue that this distinctive insight into the experiences of frontline service providers across interrelated fields is crucial when considering both applying the legislation and the theoretical concept that underpins it.

Professionals themselves have power to identify, support and act on issues of coercive control. Utilising this analysis of power, we argue that frontline services such as social workers, need to feel empowered to recognise coercive control and feel confident that the policing and justice system will utilise their power in effectively punishing offenders of coercive control. Moreover, professionals need to have the time, resources and capacity to work with victims in an empowering process to recognise coercive control and to seek the relevant help required in dealing with it. The use of discretion is an inevitable and desirable 
feature of professionals working with victims of domestic abuse. The pressing issue for service providers is to ensure that discretion is used faithfully in the face of rising demand. 


\section{NOTES}

1. In 2012, the Home Office for England and Wales introduced a new, wide-ranging and national definition of domestic abuse: Any incident or pattern of incidents of controlling, coercive, threatening behaviour, violence or abuse between those aged 16 or over who are, or have been, intimate partners or family members regardless of gender or sexuality. Previous definitions of domestic abuse used by local Forces often excluded parent-child violence and non-physical abuse such as coercive and controlling behaviour.

2. Domestic Abuse, Stalking and Honour based Violence risk assessment checklist (DASH; Richards, 2009) was introduced across all police forces in England and Wales in 2009 to provide a 'common checklist for identifying, assessing and managing risk.' http://www.dashriskchecklist.co.uk/. Drawn from analysis of domestic abuse homicides and research on risk to life in context of domestic abuse, the focus is identifying victims where likelihood of fatality is high.

3. Multi Agency Risk Assessment Conferences (MARAC) are a multi-agency forum for confidential information sharing to counter high risk cases of domestic abuse where statutory and voluntary agencies produce a coordinated plan to increase victim safety. http://www.safelives.org.uk/sites/default/files/resources/NSP\%20Guidance\%20Older\%20Peo ple\%20FINAL.pdf. MARAC's are not statutory; at the time of writing, there are approximately 270 running across the UK. 


\section{REFERENCES}

Ball, S. (2013). Foucault, Power and Education. Oxford: Routledge.

BBC (2017). Coercive control. Radio 5 Live, $23^{\text {rd }}$ April 2017.

\section{http://www.bbc.co.uk/programmes/b08mv17j/}

Bottoms, A. E. (2000). The relationship between theory and research in criminology. In R.

King, \& E. Wincup (Eds.). Doing Research on Crime \& Justice (pp. 15-60). Oxford: Oxford University Press.

Campbell, J. C., Webster, D. W., Koziol-McLain, J., Block, C., Campbell, D., Curry, M. A., et al. (2003). Risk factors for femicide within physically abusive intimate relationships: results from a multi-site case control study. American Journal of Public Health, 93,1891097.

Crossman, K. A., Hardestry, J. L., \& Raffaelli, M. (2015). “He could scare me without laying a hand on me": Mothers' experiences of nonviolent coercive control during marriage and after separation. Violence Against Women, 22, 454-473.

\section{https://doi.org:10.1177/1077801215604744}

Dobash, R. E., \& Dobash, R. P. (1992). Women, Violence and Social Change. London: Routledge.

Foucault, M. (1980a). 'Body/Power'. In C. Gordon (Ed.). Power/Knowledge: Selected Interviews and Other Writings, 1972-1977 by Michel Foucault (pp.55-62). Brighton, U.K.: Harvester.

Foucault, M. (1980b). Power/Knowledge: Selected Interviews \& Other Writings, 1972-1977. New York: Pantheon Books.

Foucault, M. (1980c). Truth and power. In C. Gordon (Ed.). Power/Knowledge: Selected Interviews and Other Writings, 1972-1977 by Michel Foucault (pp.109-133). Brighton, U.K.: Harvester. 
Glaser, B., \& Strauss, A. (1967). The Discovery of Grounded Theory: Strategies for Qualitative Research. New York: Aldine De Gruyter.

Golding, J.M. (1999). Intimate partner violence as a risk factor for mental disorders: A metaanalysis. Journal of Family Violence, 14, 99-132. https://doi.org/10.1023/A:1022079418229

Gramsci, A. (1971). Selections from the Prison Notebooks of Antonio Gramsci. New York: International Publishers.

Harne, L., \& Radford, J. (2010). Tackling Domestic Violence: Theories, Policies, \& Practice. Maidenhead: McGraw-Hill.

Hester, M. (2011). The three planet model: Towards an understanding of contradictions in approaches to women and children's safety in contexts of domestic abuse. British Journal of Social Work, 41, 837-855. https://doi.org/10.1093/bjsw/bcr095

Home Office (2012). New Definition of Domestic Violence. Accessed 18 May 2017 at https://www.gov.uk/government/publications/strategy-to-end-violence-against-womenand-girls-2016-to-2020/

Home Office (2015). Controlling or Coercive Behaviour in an Intimate or Family Relationship. Statutory Guidance Framework accessed 18 May 2017 at http://www.cps.gov.uk/legal/a_to_c/controlling_or_coercive_behaviour/

Humphreys, C., \& Thiara, R. (2003). Mental health and domestic violence: 'I call it Symptoms of Abuse'. British Journal of Social Work, 33, 209-226. https://doi.org/10.1093/bjsw/33.2.209

Johnson, M. P. (2008). A Typology of Domestic Violence: Intimate Terrorism, Violence, Resistance and Situational Violence. Boston: Northeastern University Press. 
Kelly, L., \& Westmarland, N. (2016) Naming and defining 'domestic violence': Lessons from research with violent men. Feminst Review, 112, 113-127.

https://doi.org/10.1057/fr.2015.52

Kelly, L., Adler, J. A., Horvath, M. A. H., Lovett, K., Coulson, M., Kernohan, D., Gray, M. (2013). Evaluation of the Pilot of Domestic Violence Protection Orders. London: Home Office.

Laing, L., Humphreys, C., \& Cavanagh, K. (2013). Social Work and Domestic Violence. London: Sage.

Layder, D. (1998). Sociological Practice: Linking Theory and Social Research. London: Sage.

Medina Ariza, J. J., Robinson, A. L., \& Myhill, A. (2016). Cheaper, faster, better: Expectations and achievements in police of domestic abuse. Policing, 10, 341-350. https://doi.org/10.1093/police/paw023

Myhill, A., \& Hohl, K. (2016). The "Golden Thread": Coercive control and risk assessment for domestic violence. Journal of Interpersonal Violence, 1-21. https://doi.org/10.1177/0886260516675464

Myhill, A., \& Johnson. K. (2016). Police use of discretion in response to domestic violence. Criminology \& Criminal Justice, 16, 3-20. https://doi.org/10.1177/1748895815590202

O’Brien, N., \& Moules, T. (2007). So Round The Spiral Again: A Reflective Participatory Research Project With Children and Young People. London: Routledge.

Peckover, S. (2014). Domestic abuse, safeguarding children and public health: Towards an analysis of discursive forms and surveillant techniques in contemporary UK policy and practice. British Journal of Social Work, 44, 1770-1787.

https://doi.org/10.1093/bjsw/bct042 
Pitman, T. (2016). Living with coercive control: Trapped within a complex web of double standards, double binds and boundary violations. British Journal of Social Work, 47, 143161. https://doi.org/10.1093/bjsw/bcw002

Richards, L. (2009). Domestic Abuse, Stalking and Harassment and Honour Based Violence (DASH) Risk Identification and Assessment and Management Model

\section{http://www.dashriskchecklist.co.uk/wp-content/uploads/2016/09/DASH-2009.pdf}

Robinson, A., Pinchevsky, G., \& Guthrie, J. (2016a). Under the radar: Policing non-violent domestic abuse in the UK and US. International Journal of Comparative and Applied Criminal Justice, 40, 195-208. https://doi.org/10.1080/01924036.2015.1114001

Robinson, A., Pinchevsky, G., \& Guthrie, J. (2016b). A small constellation: Risk factors informing police perceptions of domestic abuse. Policing and Society, 1-16. https://doi.org/10.1080/10439463.2016.1151881

Sharpe, K. (2000). Mad, bad and (sometimes) dangerous to know: Street corner research with prostitutes, punters and the police. In R. King, \& E. Wincup (Eds.). Doing Research on Crime And Justice. Oxford: Oxford University Press, pp. 363-372.

Stark, E. (2007). Coercive Control: How Men Entrap Women in Personal Life. New York: Oxford University Press.

Stark, E. (2013). Coercive Control. In N. Lombard, \& L. McMillan. (Eds.). Violence Against Women (pp.17-34). London: Jessica Kingsley Publishers.

Serious Crime Act (2015). Accessed at: http://www.legislation.gov.uk/ukpga/2015/9/contents/enacted

Westmarland, N., \& Kelly, L. (2012). Why extending measurements of success in domestic violence perpetrator programmes matters for social work. British Journal of Social Work, 43, 1-19. https://doi.org/10.1093/bjsw/bcs049 
Williamson, E. (2010). Living in the world of the domestic violence perpetrator: Negotiating the unreality of coercive control. Violence Against Women, 16, 1412-1423. https://doi.org/10.1177/1077801210389162

Yllo, K. (1993). Through a feminist lens: Gender, power and violence. In R. J. Gelles, \& D. R. Loseke (Eds.). Current Controversies on Family Violence. Newbury Park, CA: Sage, pp. 47-62. 


\section{AUTHOR BIOGRAPHIES}

Iain Brennan, $\mathrm{PhD}$, is reader in criminology at University of Hull and a British Psychological Society chartered research psychologist. He conducts research on the prevention of violence and on the improvement of police practice.

Nicola O'Leary, $\mathrm{PhD}$, is lecturer in criminology at University of Hull. Her research interests focus on better understandings of victims, victimisation and vulnerability. Recent funded projects have examined the wider representation of vulnerable victims and the relationship between collective victimisation and identity.

Victoria Burton is lecturer in social work at University of Hull and research interests include domestic abuse, Fathering and child protection practice.

Sinéad Gormally, $\mathrm{PhD}$, is senior lecturer in community development and adult education at the University of Glasgow. Her research interests focus on the interplay between the theoretical and practical issues relating to communities and young people. Her teaching and research interests lie in community development, youth work, social justice, as well as equality and rights-based work. 